Proc. Indian Acad. Sci. (Earth Planet. Sci.), Vol. 101, No. 3, September 1992, pp. 215-226.

(C) Printed in India.

\title{
Parametric wave prediction model based on time delay concept - An evaluation
}

\author{
J SWAIN and M BABA* \\ Naval Physical and Oceanographic Laboratory, Cochin 682021, India \\ *Centre for Earth Science Studies, Trivandrum 695031, India \\ MS received 28 February 1992; revised 29 June 1992
}

\begin{abstract}
In the early stages of wave growth it is seen that wave heights are underestimated by presently available models especially in a low wind regime. Parametric wind-sea relationships of significant wave height $\left(H_{s}\right)$ and zero-crossing period $\left(T_{z}\right)$ for slight to moderate sea-states were proposed earlier on an analysis of wind and wave data. This model is based on the concept of time delay between the wind speed $(U)$ and wave evolution process. It is simple and requires less computational effort compared to the spectral method. The present paper attempts to test and evaluate the performance of the proposed model with additional field data of wind and waves measured off the Indian coast. Measured $U, H_{s}$ and $T_{z}$ ranged between 1 and $15 \mathrm{~m} / \mathrm{s}, 0.5$ and $2.7 \mathrm{~m}$ and 4 and $10 \mathrm{~s}$ respectively. By and large, the comparison between model output and field observations are encouraging. A hindcast study was carried out earlier using a spectral wave prediction model (TOHOKU) for Indian Seas using field measurements which include the data sets utilized in this study. Comparison between these two models reveals a good agreement.
\end{abstract}

Keywords. Wave modelling; parametric wave model; time delay concept.

\section{Introduction}

The importance of wind-induced sea surface wave prediction was realized during World War II for planning of amphibious operations. Therefore, the first operational wave prediction techniques were developed by Sverdrup and Munk (1947) around that period. Subsequently, several semi-empirical wave forecasting relationships and nomograms were developed (Suthones 1945; Wilson 1955, 1983; Darbyshire and Draper 1963; Bretschneider 1970, 1973) based on the significant wave concept as that of Sverdrup and Munk. The significant wave concept, purely a statistical sense, where the spectral character of the sea-state is completely neglected. Later, the spectral character of waves led to the development of the wave spectrum methods. Currently, there are many spectral wave models used for routine wave forecasting purposes. Khandekar (1989) has compiled the present state-of-the-art on the development of wave prediction procedures and their utility for real-time operations and applications. Although there are several contributions towards development of a suitable expression for the spectral energy balance, an accurate knowledge regarding the wind-wave growth phenomenon could not be established, mainly due to lack of reliable data on wave dissipation. The SWAMP Group (1985) had carried out an intercomparison study of various wind-wave prediction models and their results revealed that none of the models were suitable for all kinds of wind fields and extreme situations. Recently, the WAM model - a third generation ocean wave prediction model (WAMDI Group 
1988) was developed in a global as well as regional domain. However, all the spectral models including the WAM model require large computational efforts. Some of them, such as parametric and coupled hybrid models such as TOHOKU II wave model (Toba et al 1985a, b) reduce the computational time through the parameterization of wind-wave growth. Hence, from the above considerations semi-empirical models require less computational time and are very useful when wind information is scarce over the specified grids of a particular region.

The present study deals with the evaluation of a parametric wave prediction model proposed by Prasada Rao and Swain (1989). This model consists of semi-empirical relationships relating the significant wave height $\left(H_{s}\right)$ and zero-crossing period $\left(T_{z}\right)$ with wind speed. The model is very simple and requires less computational effort to predict the locally developed sea-state parameters. The characteristic feature of the proposed parametric model is the introduction of time delay concept in place of wind duration which is an essential condition for wave growth. This model has been developed based on the time-series measurements of wind and waves off the west coast of India. In this paper we have tried to test and validate the model with additional field measurements. The performance of this model is also compared with a second generation spectral wave model TOHOKU (SWAMP Group 1985), whose performance was tested by Swain and Ananth (1992a) using some field measurements in the Indian Seas which also include the same data sets used in the present study.

\section{Structure and development of the model}

The growth or decay of wind-waves does not take place instantaneously with wind and there is always a time delay between the wind and wave evaluation processes. The wind and wave data used to compute the time delay belong to a local wind and wave phenomena and there were no advection of swells into the observation area. The observations were carried out hourly from a single point where the water depth was not a limiting factor for wave growth. The cross-correlation function $\left(\dot{R}_{x y}\right)$ between wind and wave $[X(t)$ and $Y(t)]$ was computed for different time-lags $(\tau)$ as given below:

$$
\bar{R}_{x y}(\tau)=\lim _{T \rightarrow \infty} \frac{1}{T} \int_{0}^{T} X(t) \cdot Y(t+\tau) \mathrm{d} t .
$$

Results of the cross-correlation analysis revealed a six hour time delay between the wind speed and significant wave height. However, the duration of the delay does not remain constant for all the wind and wave conditions but depends on the speed and duration of the wind blowing steadily from one direction. In this case wind speed was variable but direction was more or less steady during the collection of data used for development of the present model.

One of the most important requirements for the prediction of sea-state is the input wind speed and direction. In the absence of wind over the entire oceanic region where we intend to run a prediction model, it is extremely difficult to predict the sea-state, particularly the swell waves. However, the local wind-wave phenomena can be predicted to a reasonable accuracy using wind observations from a single point which does not show significant variations (over $\pm 30^{\circ}$ ) in direction and the fetch remains considerably longer. Hence, the present model was designed in such a way that it 
could predict the local wind-wave phenomena such as wind-seas and swells which may result due to decrease of wind speed or a gradual change in wind direction. As the cross-correlation analysis revealed that the sea-state is more dependent on the past wind field compared to the present wind, this model uses past sixth hour wind speed $\left(U_{6}\right)$ and present wind speed $\left(U_{0}\right)$ to predict the existing sea-state. The relationships between wind speed and the significant parameters of the sea-state which constitute the present model (Prasada Rao and Swain 1989) are as follows:

$$
\begin{aligned}
& H_{s}=U_{0}\left(A+B \cdot U_{6}^{2}\right) \times\left(U_{0}^{1 / 2}+C\right)^{-1}, \\
& T_{z}=a+b\left(U_{0} \cdot U_{6}\right)^{3 / 8}+\log _{10}\left[\left(U_{6}+U_{0}^{1 / 4}\right) \cdot U_{0}^{-1}\right]^{9 / 4},
\end{aligned}
$$

where $A=0.56, B=0.0047, C=1.5, a=3.7$ and $b=0.102$. The wind speeds $(\mathrm{m} / \mathrm{s}), U_{0}$ and $U_{6}$ are at $10 \mathrm{~m}$ from the sea surface. In equation (3), $T_{z}$ may be replaced by significant wave period $\left(T_{g}\right)$ since it is apt to be the average period of all waves whose troughs are below and erests are above the mean water level (Shore Protection Manual 1984) as in the case of $T_{z}$ in zero-crossing analysis (Tucker 1983; Draper 1967).

The above relationships [equations (3) and (4)] were obtained through least square and power law approximations. However, the values of the above mentioned arbitrary constants were evaluated and subsequently replaced through sensitivity analysis (Prasada Rao and Swain 1989). It is to be noted that the model is not valid on dimensional considerations and not to be used during extreme wind conditions. It is formulated such that, it can predict the moderate sea-state conditions where it is usually difficult to estimate fetch and duration of wind due to the fluctuating nature of the prevailed wind-field.

The wind and wave parameters used in the development of (2) and (3) were collected off Goa (figure 1), west coast of India. The observed and predicted wave parameters are shown in figure 2 with thick continuous and dotted lines respectively. The winds

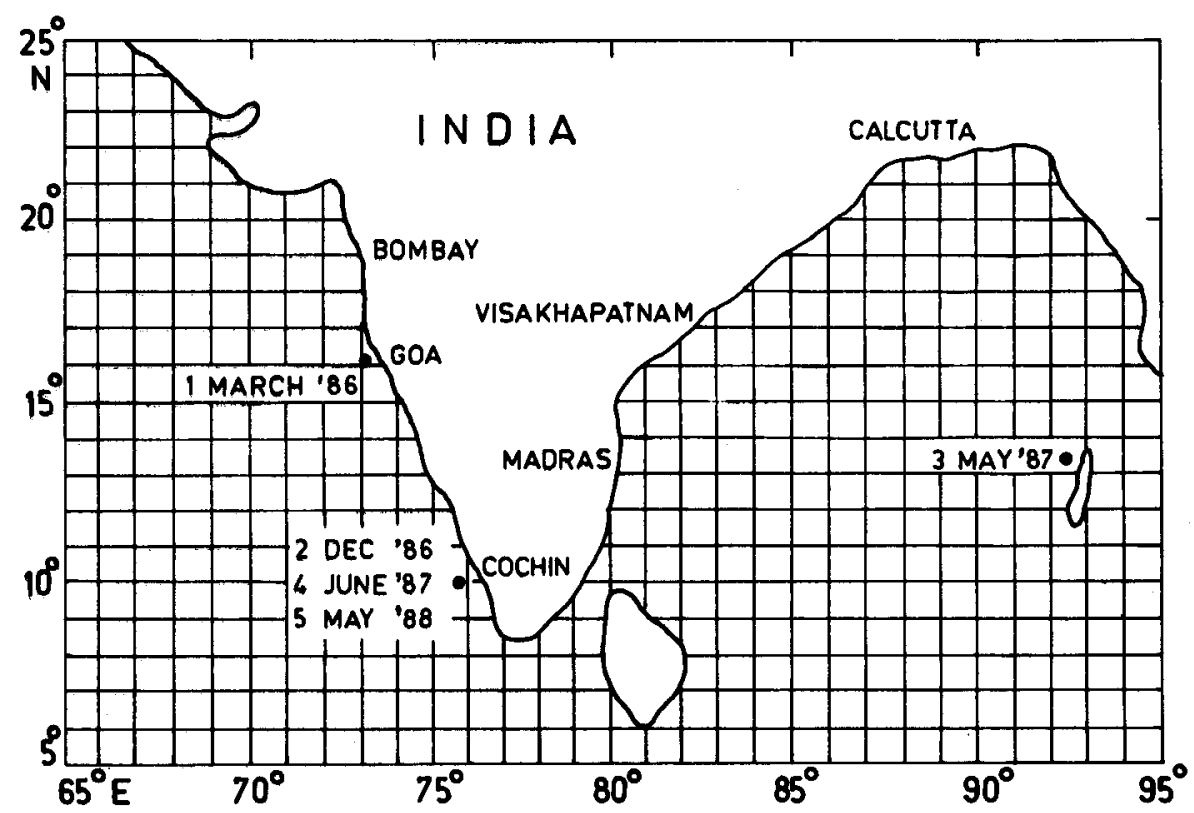

Figure 1. Station location map. 
(a)

RVG CR. NO.-165, OFF GOA

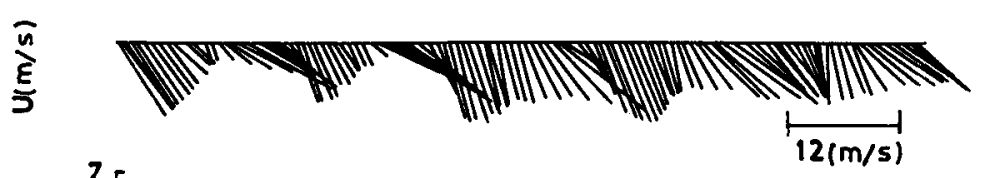

(b)

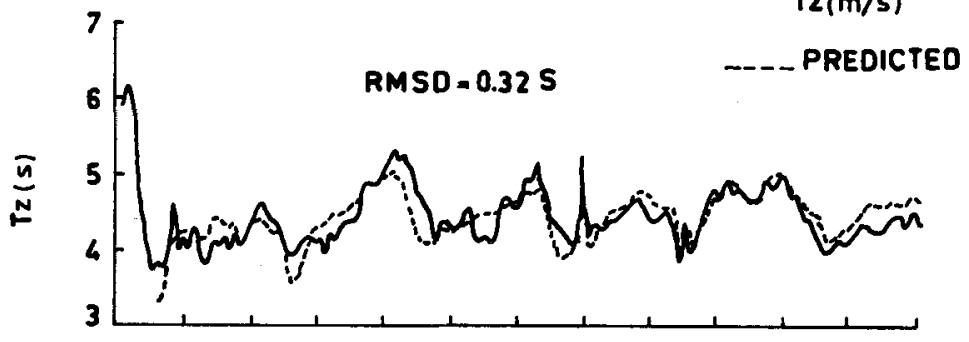

(c)

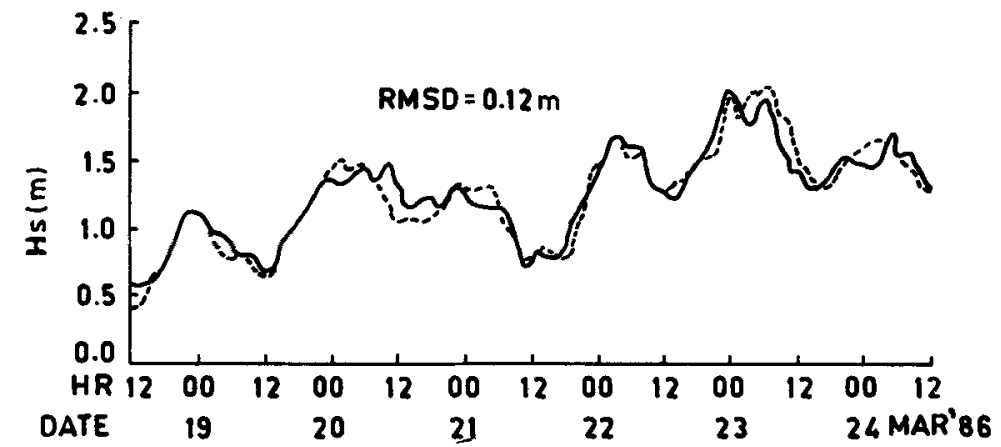

Figure 2. (a) The observed wind; (b) Comparison between predicted and observed $T_{z}$ and (c) Comparison between predicted and observed $H_{s}$ (Prasada Rao and Swain 1989).

are shown in the form of stick plots (figure 2). Prasada Rao and Swain (1989) found that the comparisons between the predicted and observed wave parameters were quite encouraging (figure 2) with root mean square deviations of $0.12 \mathrm{~m}$ and $0.32 \mathrm{~s}$ respectively for $H_{s}$ and $T_{z}$.

\section{Data and methods}

Hourly time-series of wind and waves were carried out during four different cruises of an oceanographic research vessel GAVESHANI (RVG) in the coastal waters off Cochin in the Arabian Sea and off Andamans in the Bay of Bengal (figure 1). During each cruise, DATAWELL wave-rider buoy was moored and wave records were collected onboard the ship anchored in the vicinity of the buoy. Each wave record is of 20 minutes duration with a sampling rate of $0.5 \mathrm{~s}$. Wind speed and direction were continuously recorded by installing Dyna-Vane wind recording system (T.S.K., Japan, model-112) onboard the ship at $10 \mathrm{~m}$ from the sea surface. The measured wind speed and direction have accuracies of $\pm 0.5 \mathrm{~m} / \mathrm{s}$ and $\pm 5^{\circ}$ respectively. The wind directions were measured from true north considering the ship's head as the reference and the necessary corrections were made to compute true wind directions. The observed $H_{s}$ and $T_{z}$ are obtained from the records of sea surface elevation through standard FFT 
analysis (Bendat and Piersol 1971). As the fully-developed wave height is directly proportional to the square of the wind speed (Carter 1982) and dependent on the duration of wind for a given fetch, the mean wind speed is computed as follows (Douglas et al 1976; Swain and Prasada Rao 1987):

$$
\begin{aligned}
\bar{U}_{0}= & \frac{1}{\sqrt{5}}\left[\left\{5 \alpha\left(U_{0} \sin \theta_{0}\right)^{2}+(1-\alpha)\left(\left(U_{1} \sin \theta_{1}\right)^{2}+\ldots+\left(U_{5} \sin \theta_{5}\right)^{2}\right)\right\}^{\frac{1}{2}}\right. \\
& \left.+\left\{5 \alpha\left(U_{0} \cos \theta_{0}\right)^{2}+(1-\alpha)\left(\left(U_{1} \cos \theta_{1}\right)^{2}+\ldots+\left(U_{5} \cos \theta_{5}\right)^{2}\right)\right\}^{\frac{1}{2}}\right]
\end{aligned}
$$

where $U_{1} \ldots U_{5}$ and $\theta_{1} \ldots \theta_{5}$ are the past first to fifth hours wind speed and direction. The value of $\alpha=0.5$.

Equation (4) uses both vectorial and weighted averaging of $U^{2}$ which is proportional to the wave energy. As the wind varies rapidly both in speed and direction, it was important to estimate the mean wind using the past observations carefully (Swain and Prasada Rao 1987). Such averaging helps to estimate the sea-state during low wind periods if the wind is varying rapidly or during the early stages of wave growth when the wind is stronger.

Similarly, the mean wind direction is computed through weighted averaging by giving proper weightage to wind speed as shown below:

$$
\bar{\theta}_{0}=\frac{\alpha \theta_{0} \bar{U}_{0}+(1-\alpha)\left(\theta_{1} \bar{U}_{1}+\ldots+\theta_{5} \bar{U}_{5}\right)}{\alpha \bar{U}_{0}+(1-\alpha)\left(\bar{U}_{1}+\ldots+\bar{U}_{5}\right)} .
$$

where $\bar{U}_{0} \ldots \bar{U}_{5}$ and $\theta_{0} \ldots \theta_{5}$ are the present to past fifth hour mean wind speed [equation (4)] and direction respectively.

It is assumed that the existing wind-seas propagate in the mean wind direction as obtained from (5). In this study, corrections are made for both $H_{s}$ and $T_{z}$ when there is a change in wind direction. This was found essential due to the overprediction of these parameters during such situations. If the mean wind direction of past sixth hour changes $(\delta \theta)$ by $>30^{\circ}$ compared to the existing direction then $H_{s}$ and $T_{z}$ are replaced by $H_{s} \cdot(\cos \delta \theta)^{\frac{1}{2}}$ and $T_{z} \cdot(\cos \delta \theta)^{\frac{1}{4}}$. However, if $\delta \theta>60^{\circ}$ this model may not be able to predict the sea-state correctly. In such cases $\left(\delta \theta>60^{\circ}\right)$, the original wave height and period are assumed, since the fetch is considered as unlimited. Therefore, this model is purely statistical and is suitable for wind conditions generally prevailing in the Arabian Sea and Bay of Bengal.

\section{Results and discussion}

In this study, we consider four hindcast cases to compare between observed and hindcast results obtained from this model using equations (2) and (3). The word prediction is used hereafter instead of hindcasting. Details regarding the source of data, comparisons between the model simulated and observed wave parameters along with their mean deviations ( $\%$ MD) and root mean squared deviations (\% RMSD) are given in table 1 . Values of MD and RMSD computed using the TOHOKU model (Swain and Ananth 1992a) are also given along with that of the present model. All the data sets in this study are collected from the coastal waters in the shelf region where the water depth $(d)$ varies from 60 to $80 \mathrm{~m}$. However, most of the wave observations 
Table 1. Comparison of predicted and observed wave parameters.

\begin{tabular}{|c|c|c|c|c|c|}
\hline $\begin{array}{l}\text { Test } \\
\text { case }\end{array}$ & & $\begin{array}{c}\text { Case I } \\
\text { (figure 3) }\end{array}$ & $\begin{array}{c}\text { Case II } \\
\text { (figure 4) }\end{array}$ & $\begin{array}{r}\text { Case III } \\
\text { (figure 5) }\end{array}$ & $\begin{array}{c}\text { Case IV } \\
\text { (figure 6) }\end{array}$ \\
\hline Area & & Arabian Sea & Bay of Bengal & Arabian Sea & Arabian Sea \\
\hline Position & & $\begin{array}{l}09^{\circ} 57 \cdot 6^{\prime} \mathrm{N} \\
75^{\circ} 45 \cdot 0^{\prime} \mathrm{E}\end{array}$ & $\begin{array}{l}12^{\circ} 26 \cdot 0^{\prime} \mathrm{N} \\
92^{\circ} 23 \cdot 2^{\prime} \mathrm{E}\end{array}$ & $\begin{array}{l}09^{\circ} 45 \cdot 5^{\prime} \mathrm{N} \\
75^{\circ} 51 \cdot 1^{\prime} \mathrm{E}\end{array}$ & $\begin{array}{l}09^{\circ} 47 \cdot 5^{\prime} \mathrm{N} \\
75^{\circ} 44 \cdot 4^{\prime} \mathrm{E}\end{array}$ \\
\hline Depth $(m)$ & & 65 & 80 & 60 & 75 \\
\hline Period & & Dec. 1986 & May 1987 & June 1987 & May 1988 \\
\hline $\begin{array}{l}\text { No. of } \\
\text { observations }\end{array}$ & & 96 & 78 & 48 & 138 \\
\hline $\begin{array}{l}\text { Wind speed ( } m \\
\text { and direction }\end{array}$ & & $\begin{array}{l}1 \text { to } 10 \\
\text { NNW }\end{array}$ & $\begin{array}{c}4 \text { to } 9 \\
\text { NNW-NNE }\end{array}$ & $\begin{array}{c}10 \text { to } 15 \\
\text { NW }\end{array}$ & $\begin{array}{l}1.5 \text { to } 9 \\
\text { NNW }\end{array}$ \\
\hline $\begin{array}{l}\text { Significant } \\
\text { wave height } \\
\left(\mathrm{H}_{s}\right)\end{array}$ & $\begin{array}{c}\text { Range }(m) \\
\% \text { MD } \\
\% \text { RMSD }\end{array}$ & $\begin{array}{c}0.5 \text { to } 1.0 \\
-34.8 \\
(-27.6)^{*} \\
40.6 \\
(33.2)\end{array}$ & $\begin{array}{c}0.5 \text { to } 1.0 \\
-10.5 \\
(8.7) \\
14.8 \\
(18.3)\end{array}$ & $\begin{array}{c}2.0 \text { to } 2.7 \\
8.0 \\
(3.8) \\
19.5 \\
(12.8)\end{array}$ & $\begin{array}{c}0.8 \text { to } 1.4 \\
-8.9 \\
(-14.5) \\
19.1 \\
(20.5)\end{array}$ \\
\hline $\begin{array}{l}\text { Zero-crossing } \\
\text { period }\left(T_{z}\right)\end{array}$ & $\begin{array}{c}\text { Range (s) } \\
\% \mathrm{MD} \\
\% \text { RMSD }\end{array}$ & $\begin{array}{c}4.0 \text { to } 6.7 \\
-10.6 \\
(17.4) \\
18.1 \\
(24.3)\end{array}$ & $\begin{array}{c}4.6 \text { to } 9.9 \\
-32.8 \\
(-25.0) \\
35.3 \\
(30.0)\end{array}$ & $\begin{array}{c}6.0 \text { to } 7.6 \\
-13.0 \\
(3.8) \\
16.5 \\
(10.8)\end{array}$ & $\begin{array}{c}5.0 \text { to } 8.0 \\
-22.3 \\
(-16.0) \\
24 \cdot 4 \\
(20.0)\end{array}$ \\
\hline
\end{tabular}

* \%MD and \% RMSD for the TOHOKU model are given inside parentheses.

satisfy the deep water condition ( $d>L / 2, L$ is wave length). The individual case studies are discussed separately. Some typical wave spectra for all the data sets are given in an earlier study (Swain and Ananth 1992b).

\subsection{Case I}

The comparisons between predicted and observed $H_{3}$ and $T_{z}$, and observed wind speed are shown in figure 3 . This data set was collected during December when the Arabian sea generally remained calm (fair weather). During the period of data collection wind direction was more or less steady (around northerly). It should be noted that as the wind directions in all the test cases have varied slowly $\left(\delta \theta>30^{\circ}\right.$ over $90 \%$ cases), instead of wind sticks only the wind speeds are plotted in the respective figures for better visualization. The spectral analysis (Swain and Ananth 1992b) of this data set reveal that, most of the spectra are double peaked and the major peak corresponds to swell waves. However, there is a significant influence of the wind over the prevailing waves noticed from the growth of wind-sea peak during the increase of wind speed. According to the classification of Thompson et al (1984), the values of significant steepness for the above spectra indicate that $40 \%$ of the observations are young swells and $20 \%$ are old swells which are being maintained by the local wind. The remaining observations corresponding to higher wind speeds $(U>5.0 \mathrm{~m} / \mathrm{s})$ are predominantly wind-seas $(40 \%)$ where the swell energy is comparatively insignificant. 


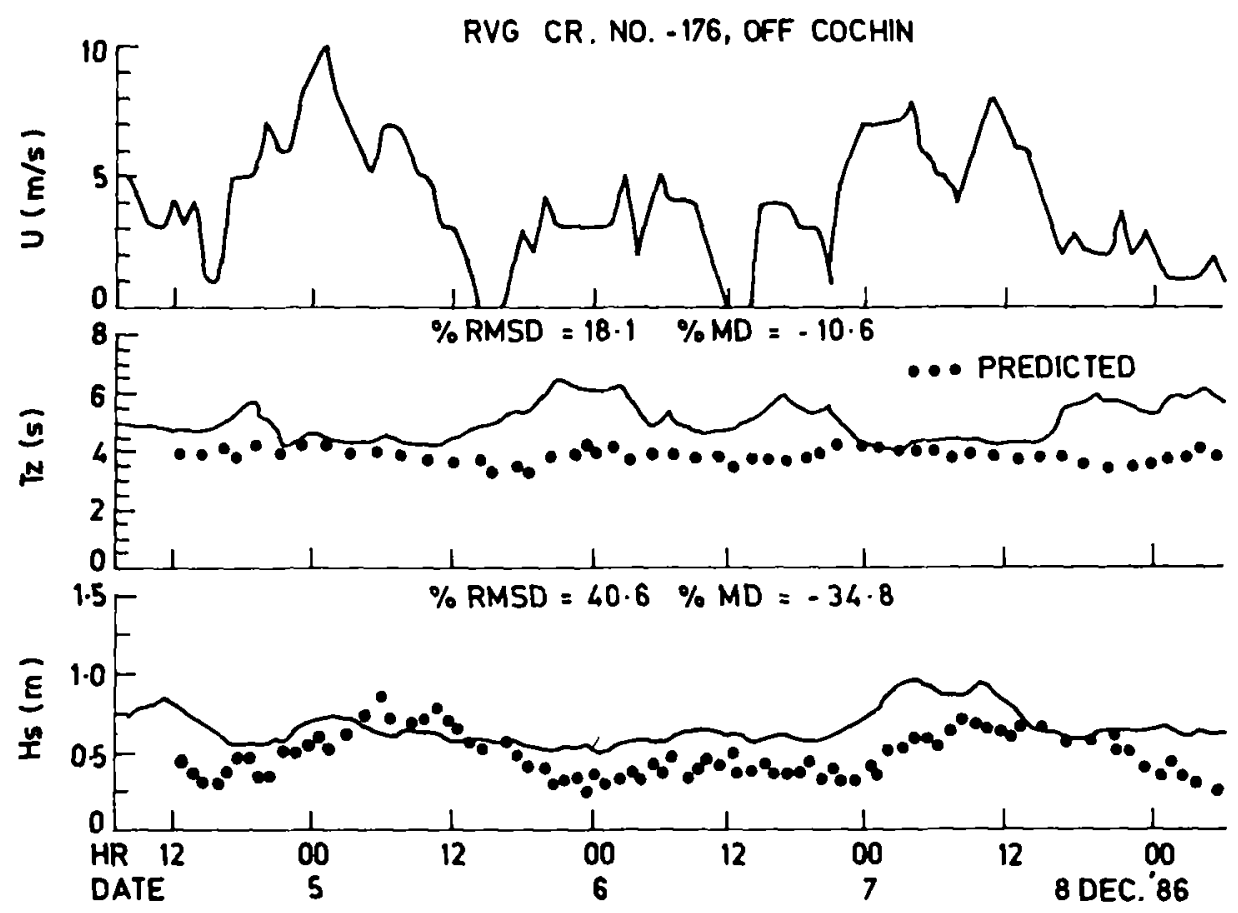

Figure 3. Same as figure 2 for case I.

It is seen that for the higher wind speed regions $(U>5.0 \mathrm{~m} / \mathrm{s})$, predicted $H_{s}$ and $T_{z}$ are well compared with the observed values. In general, the agreement between predicted and observed $T_{z}$ is better compared to $H_{s}$. During the low wind regime corresponding to the middle of the observation period, the model retains the wave height and period to a reasonable extent eventhough the wind speed has dropped abruptly. However, $T_{z}$ increased to a greater extent presumably due to the presence of swell waves as discussed above. The MD for $H_{s}$ indicate that the predicted values are under estimated by about $35 \%$.

\subsection{Case II}

This data set was collected during the pre-onset phase of south-west monsoon (May). The routine analysis of this data was carried out by Swain and Prasada Rao (1989) which present the observed features along with the prevailing wind. During the period of data collection, wind speed was relatively higher (predominantly 4 to $9 \mathrm{~m} / \mathrm{s}$ ) compared to the climatological surface winds which prevail around the observation area off Andaman and Nicobar Islands in the Bay of Bengal (figure 1). Wind direction varied slowly between NNW and NNE. The wave spectra for the entire observation period except for a few during the peak wind speeds (figure 4) reveal a major swell peak which is independent of the prevailing wind. However, the predicted $H$, values are in better agreement with the observed values. Due to the presence of swells, the predicted $T_{z}$ is relatively underestimated except when the wind speed show its peaks thrice during the period of observation $(U>5.0 \mathrm{~m} / \mathrm{s})$. 


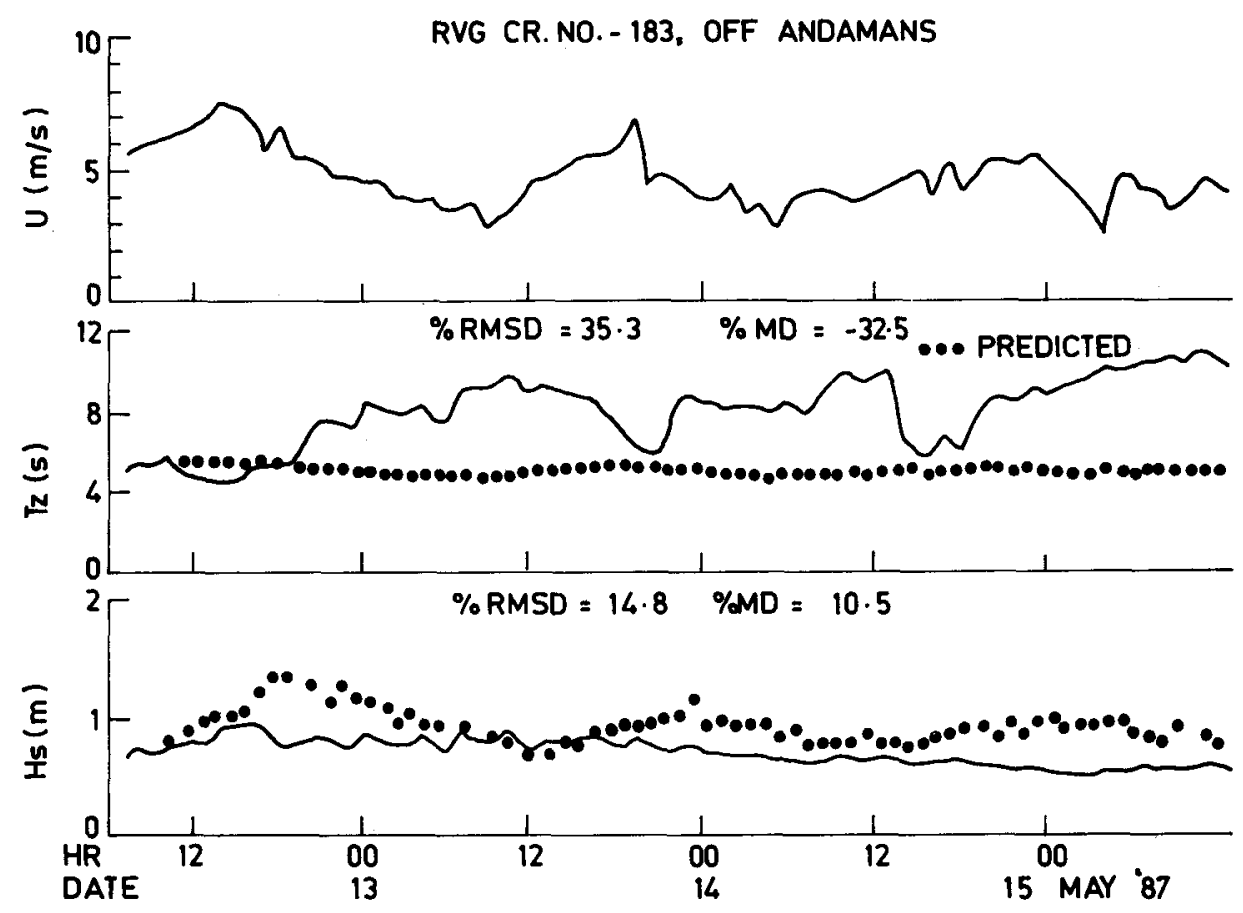

Figure 4. Same as figure 2 for case II.

\subsection{Case III}

This data was collected during the active south-west monsoon period over the Arabian Sea. During this period the wind speed was around 10 to $15 \mathrm{~m} / \mathrm{s}$ and the direction was fairly steady (NW-NNW) except for a slight change for the last few observations. During the south-west monsoon, the wind speed is generally high and blows over a long distance in the Indian Seas. In this case, the predicted wave parameters agree fairly well with the observed conditions (figure 5). However, during the middle of the observation period, the predicted $H_{s}$ is overestimated as the wind speed is high during that phase. This might be due to the change in direction of monsoon flow at the observation site on the shelf. To make this point more clear, the wind which is south-west in the open ocean usually turns west and then north of north-west as it approaches the west coast (land boundary). Hence the prevailing wind at the observation site may oppose the waves that are either in the south-west direction or perpendicular to the coast line. By and large, it is evident that the present model might predict the wave conditions fairly well during moderate wind conditions ( 5 to $15 \mathrm{~m} / \mathrm{s}$ ) which remain more or less same in the open sea and near the coast mostly during south-west monsoon except for a gradual change in its direction.

\subsection{Case IV}

This data set was collected in May during south-west monsoon period, but the wind speed was comparatively weak varying from 1.5 to $9 \mathrm{~m} / \mathrm{s}$. Wind direction was more 


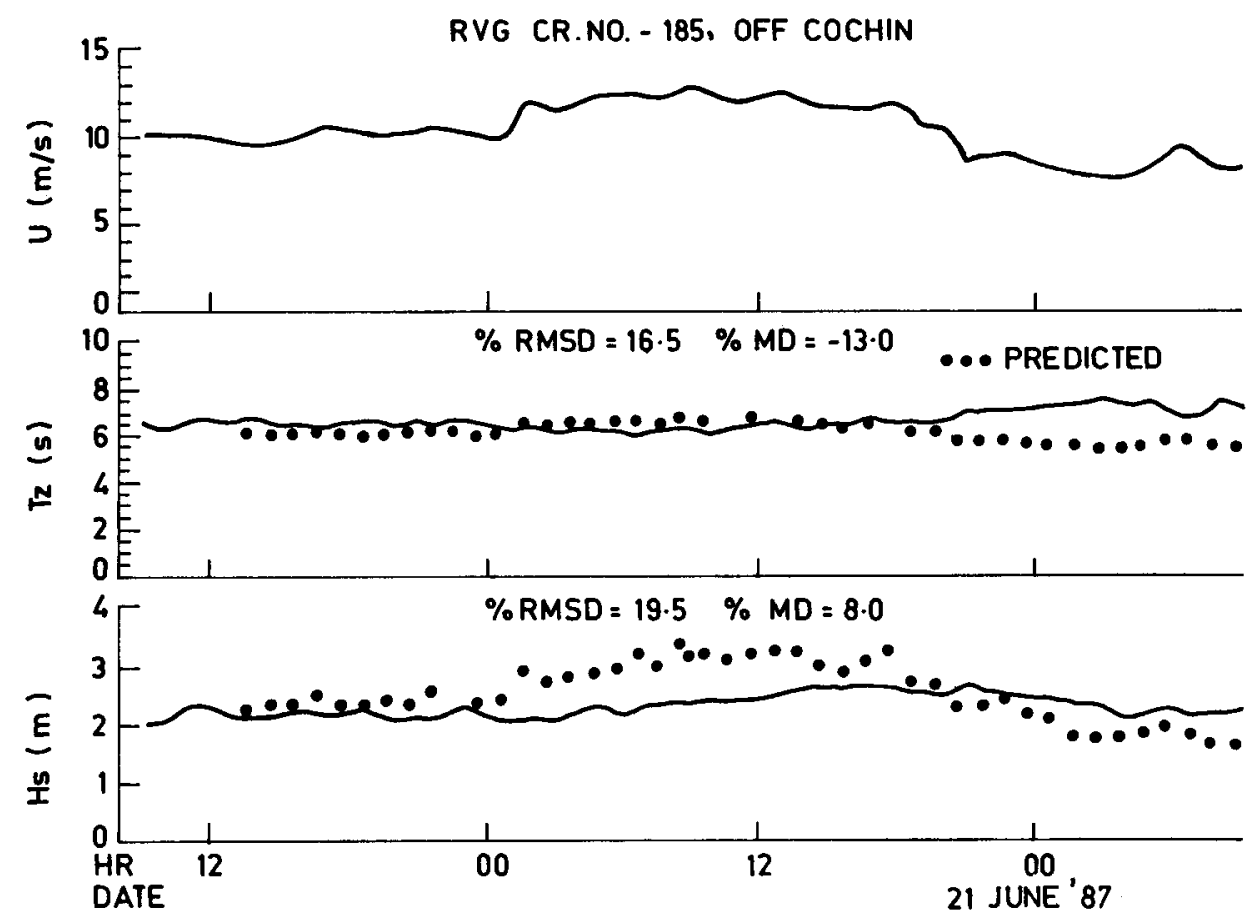

Figure 5. Same as figure 2 for case III.

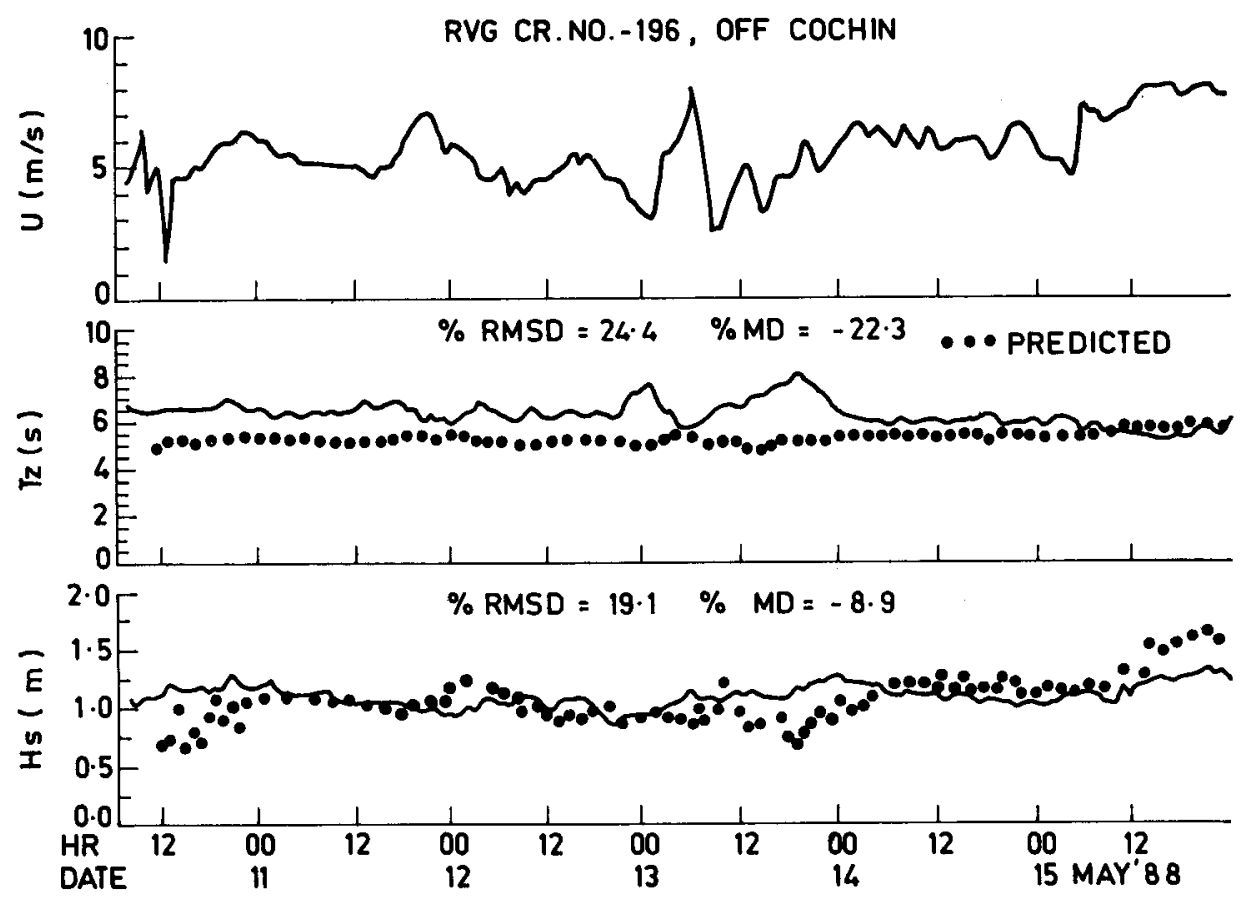

Figure 6. Same as figure 2 for case IV. 
or less steady around (NNW). For the last two days (14th and 15th) the peak frequency was consistent but for the rest of the observation period it was shifting from wind-sea to swell region and vice-versa. The comparisons between predicted and observed $H_{s}$ and $T_{z}$ are quite good for the last two days of observation period (figure 6). However, although the predicted $H_{s}$ agrees well with the observed values, there is more or less a consistent departure between the predicted and observed $T_{2}$ except on the last two days. Hence, these waves might have been generated by nearby sources and are propagating into the observation point as young swells which are maintained by the prevailing local wind field.

\subsection{Comparison with TOHOKU model}

The TOHOKU model belongs to the class of coupled-hybrid wave models which combines a single parameter growth equation for wind waves with the swell components and includes an exchange between windwaves and swells. Swain and Ananth (1992a) carried out a hindcast study using wind input from a single point for a few test cases. The assumption is that the wind field surrounding the observation point remains the same for at least an hour which is the time step considered for simulation. The results showed that, the TOHOKU model is quite successful during local wind and wave activity though hourly time-series of wind is used for prediction.

The MD and RMSD values of the present model and the TOHOKU model (inside parentheses) are shown in table 1 . For cases I to III, the predicted $H_{s}$ using the TOHOKU model is in better agreement with observed values by about 2 to $7 \%$ compared to the present model. However, in case IV the present model gives a better prediction by $6 \%$. The MD is negative for case I and case IV and positive for case III for both models. In case II, the performance of both the models is more or less equal, but the MD is negative $(-10.5 \%)$ for the present model and positive (8.7\%) for the TOHOKU model. The predicted $T_{z}$ using the present model is underestimated for all the cases while the TOHOKU model overestimates it in cases I and III. The TOHOKU predicts $T_{2}$ with minimum deviation ranging from 6 to $9 \%$ compared to the present model whereas the former deviates more by $6 \%$ in case $I$. In general, both MD and RMSD values for $H_{3}$ and $T_{2}$ using both the models vary marginally within $\pm 9 \%$. Hence, the agreement between both the models is quite encouraging for all the cases discussed above.

\section{Conclusions}

The performance of the parametric wave prediction model based on time delay concept proposed by Prasada Rao and Swain (1989) is quite encouraging for the present case studies. Hindcasting of the significant wave parameters such as height and period agrees well with the observed parameters with an average RMSD of $23.5 \%$ considering all the four case studies. Since the data sets used for evaluation of the present model are not purely the result of local wind wave phenomena and as the model uses the time-series wind collected at a single location in the sea and assumes an unlimited fetch, it can only predict the sea-state to a certain degree of accuracy. Considering the above difficulties the model is quite satisfactory and may be useful in short-term prediction purposes ( 3 to 6 hours) during a local wind and wave phenomena. It is to 
be noted that the model is developed from the time-series measurements of wind and waves from a single location in the sea through least square and power law approximations. Therefore the semi-empirical relationships of the model are not valid from dimensional considerations.

The model is very simple and it requires less computational efforts and may be very useful when the wind measurements are not available for the entire oceanic region for wave hindcasting or prediction purposes. The characteristic feature of the model is the introduction of time delay concept which can replace the duration limit of the wind. Moreover, estimation of wind duration and fetch often becomes too difficult due to the fluctuating nature of the wind particularly during moderate sea-state conditions generally prevailing in the Indian Seas.

The present model is compared with the TOHOKU model which is a second generation coupled hybrid model based on spectral approach. The comparison is encouraging for the wind and wave data sets considered in this study. It is hoped that the model would prove to be handy in the short-term prediction of local wave activity.

\section{Acknowledgements}

The authors wish to express their gratitude to the Director, Naval Physical and Oceanographic Laboratory, Cochin for facilities, to the Director, National Institute of Oceanography, Goa for providing the ship facility during data collection programs and to the Director, Centre for Earth Science Studies, Trivandrum for encouragement.

\section{References}

Bendat J S and Piersol A G 1971 Random data-analysis and measurement processes (New York: John Wiley) pp 304

Bretschneider C L 1970 Forecasting relations for wave generations; Look Lab/Hawaii, University of Hawaii, USA 1 31-34

Bretschneider C L 1973 Prediction of waves and currents; Look Lab/Hawaii, University of Hawaii, USA 3 No. 1

Carter D J T 1982 Prediction of wave height and period for constant wind velocity using the JONSWAP results; J. Ocean Eng. 9 17-33

Darbyshire M and Draper L 1963 Forecasting of wind generated sea waves; Engineering 195 127-134

Draper L 1967 The analysis and presentation of wave data - A plea for uniformity; Proc. 10th Conf. on Coastal Engg., Tokyo, Japan 1 1-11

Douglas C, Montgomery and Lynwood A John 1976 Forecasting time series analysis (McGraw-Hill, New York) pp 304

Khandekar M L 1989 Operational analysis and prediction of ocean wind waves (New York, Springer Verlag) pp 214

Prasada Rao C V K and Swain J 1989 A parametric wave prediction model based on time delay concept; Mausam $40381-388$

Shore Protection Manual 1984 US Army Corps of Engineers. Washington DC

Suthones C T 1945 The forecasting of sea and swell waves. Naval Meteorological Branch, UK, Tech. Memo 135/45

Sverdrup H U and Munk W H 1947 Wind, Sea and Swell: Theory of relations for forecasting; US Navy Hydrogra. Office, Washington DC, Pub. No 601

Swain J and Prasada Rao C V K 1987 A single parametric representation for growing wind seas; Symposium 
on short-term variability of physical oceanographic features in the Indian waters, Naval Physical and Oceanographic Laboratory, Cochin, 201-204

Swain J and Ananth P N 1992a Wave hindcasting using a coupled hybrid wave prediction model in Indian Seas; J. Ocean Engg. (in press)

Swain J and Ananth P N 1992 b Observed deep water wave characteristics off Indian Coasts; Indian J. Mar. Sci. (in press)

Swain J and Prasada Rao C V K 1989 A note on the observed surface wave characteristics off Madras to Andamans during May 1987; Departmental Res. Report. NPOL, No RR-4/89

Thompson W C, Nelson A R and Sedivy D G 1984 Wave group anatomy; Proc. 19th Coastal Engg. Conference, ASCE, 1 pp 661-677

The SWAMP Group 1985 Ocean Wave Modelling (New York: Plenum) pp 256

Toba Y, Kawai S and Joseph P S 1985 The TOHOKU Wave Model (The SWAMP Group, Ocean Wave Modelling) (New York: Plenum Press) pp 256

Toba Y, Kawai S, Okada K and Iida N 1985 The TOHOKU-II Wave Model, The Ocean Surface, (eds.) Y Toba and Mitsuyasu (Dordrecht: D Reidel) pp 227-232

Tucker M J 1963 Analysis of records of sea waves; Proc. Inst. Civil Engg., London $26305-316$

WAMDI Group 1988 The WAM model - A third generation ocean wave prediction model; J. Phys. Oceanogr. 18 1775-1810

Wilson B W 1955 Graphical approach to the forecasting of waves in moving fetchs; Beach erosion board, US Army Corps of Engineers Tech. Memo. No 73, pp 31

Wilson B W 1983 Deep water generation by moving wind systems; Trans. Am. Soc. Civil. Eng. 128, Paper No. 3416 